\title{
Bleaching stress on Indian coral reef regions during mass coral bleaching years using NOAA OISST data
}

\author{
Mohit Arora $^{1,2, *}$, Nandini Ray Chaudhury ${ }^{1}$, Ashwin Gujrati ${ }^{1}$ and \\ Ramesh Chandra Patel ${ }^{2}$ \\ ${ }^{1}$ Space Applications Centre, Indian Space Research Organisation, Ahmedabad 380 015, India \\ ${ }^{2}$ Department of Geophysics (Applied), Kurukshetra University, Kurukshetra 136 119, India
}

Coral reefs are one of the most ancient, highly productive marine bio-diverse ecosystems on earth. They are threatened to collapse under rapid climate change. ENSO is an extreme climate change event which elevates sea-surface temperature (SST) of tropical oceans. This elevated SST increases the level of thermal stress on coral reefs. Also, coral reefs are the most sensitive among all ecosystems due to temperature change; they exhibit bleaching when SST exceeds normal summer maxima and remains high for more than 28 days. Bleaching threshold, positive SST anomaly and degree heating week (DHW) are commonly used indices for calculating thermal stress on coral reefs. The major coral reef regions in India are Andaman, Nicobar, Lakshadweep, Gulf of Mannar and Gulf of Kachchh. SST from NOAA OISST v2 highresolution daily dataset at $0.25^{\circ}$ global grids from 1982 to the present was used for the present study. Here, we focus on the variations in SST experienced by Indian coral reef regions during known mass coral bleaching (MCB) years, viz. 1998, 2010 and 2016. The year 2010 recorded the highest thermal stress for Andaman, Nicobar and Gulf of Kachchh regions, and the year 2016 was severe for Lakshadweep and Gulf of Mannar regions. In 2010 Nicobar was observed to be the most vulnerable according to DHW index.

Keywords: Bleaching threshold, degree heating week, mass coral bleaching, sea surface temperature.

CORAL reef ecosystems provide habitat for over a million of species and are important for the socio-economic wellbeing of approximately 500 million people ${ }^{1,2}$. Reefs also act as barriers to wave action and storm surges and protect the coastline. They provide economic resources through tourism and fisheries for an estimated half a billion people living within $100 \mathrm{~km}$ of the reefs ${ }^{3}$.

The growth and survival of coral reefs depend on many physical variables, including sea-surface temperature (SST), irradiance, calcium carbonate saturation, salinity, $\mathrm{pH}$, nutrients, turbidity and sedimentation. These

\footnotetext{
*For correspondence. (e-mail: mohitarorakuk12@gmail.com)
}

variables influence the physiological processes of photosynthesis and calcification, and as a result coral reefs occur in select areas of the world's oceans ${ }^{3}$. Currently, reef-building corals persist within relatively narrow environmental conditions ${ }^{4}$. The carbonate reef structures commonly build up in the tropical regions where seawater temperature exceeds $18^{\circ} \mathrm{C}$ in winter and remains below $28^{\circ} \mathrm{C}$ in summer ${ }^{5}$.

Coral reefs are the most sensitive among coastal ecosystems to SST changes ${ }^{6}$. During 1997-98, 2010 and 2015-16, El Niño Southern Oscillation (ENSO) events occurred in tropical oceans ${ }^{7}$. These are the expression of climate change events which elevated SST in the Indian seas $^{8,9}$. Elevated SST is considered a major cause for worldwide coral bleaching ${ }^{10}$. SST extremes impact corals with thermal stress ${ }^{11}$. Under stress, symbiotic zooxanthellae get expelled by coral polyps leading to bleaching of the coral tissues. Coral bleaching is one of the major threats which significantly affects the reefs ${ }^{12}$. SST is a critical physical attribute of marine coastal ecosystems and directly affects process rates, water column stability and distribution of plants (e.g. algae, seagrass, marsh plants, mangroves) and animal species (microscopic animals to large invertebrates, fish and mammals) inhabiting the ecosystem.

Mass coral bleaching (MCB), mortality and their effects on reefs at regional scale have been observed worldwide and reported since the early 1980s (ref. 13). During 1997-98, 2010 and 2015-16, the MCB events severely affected coral reefs all over the globe and caused mortality ${ }^{7}$. The first well-known MCB event occurred in 1998, wherein approximately $16 \%$ of reef-building corals were bleached worldwide ${ }^{1}$. The second global MCB event was reported in 2010. The third global MCB event in 2016 was the longest one on record ${ }^{7}$. During the 2015$16 \mathrm{MCB}$ event, the Great Barrier Reef (GBR) in Australia experienced unprecedented levels of coral bleaching on a large scale ${ }^{14}$.

Indian coral reef regions have experienced MCB events during 1998, 2010 and 2016 (refs 9, 15-17). Although corals can re-establish themselves after $\mathrm{MCB}$, in some cases it takes one to two decades for the entire ecosystem 
to return to the pre-bleaching state ${ }^{18}$. An increase in the frequency and severity of MCB could overwhelm the ability of coral reefs to recover between the events. If this occurs, coral reef ecosystems would shift towards systems that are dominated by other organisms such as cyanobacteria and algae ${ }^{5}$.

Satellite assessment of thermal stress has focused primarily on $\mathrm{SST}^{19}$. MCB and consequent mortality are the result of accumulation of thermal stress in terms of time over continuous weeks, expressed as a popular bleaching index, viz. degree heating week $(\mathrm{DHW})^{20}$. The National Oceanic and Atmospheric Administration (NOAA) Coral Reef Watch (CRW) programme uses the DHW index to assess thermal stress on coral reefs based on satellitederived daily $\mathrm{SST}^{21}$. Weekly thermal anomalies greater than $1{ }^{\circ} \mathrm{C}$ above a climatological mean SST (or maximum monthly mean SST) are summed over a 12-week period, which results in $\mathrm{DHW}^{22}$. In situ monitoring of coral bleaching is practically difficult due to manpower and resource-intensive field/ground survey.

The objective of this study was to carry out an assessment of thermal stress on Indian coral reef regions during the three major MCB years, and further our understanding on coral bleaching. NOAA Optimum Interpolated Sea Surface Temperature (OISST) version 2 data were analysed for Indian coral reef regions and coral bleaching indices were computed.

\section{Study area}

The five major Indian coral reef regions: Andaman, Nicobar, Lakshadweep, Gulf of Mannar and Gulf of Kachchh geographically lie at different latitudes on the Indian coast (see Figure 1) ${ }^{23}$.

The geographical co-ordinates of Andaman and Nicobar (A\&N) Islands are $6^{\circ}-14^{\circ} \mathrm{N}$ lat. and $92^{\circ}-94^{\circ} \mathrm{E}$ long. The A\&N Islands are one of the Union Territories of India, located in the eastern part of the Bay of Bengal. Lakshadweep Islands lie in the Arabian Sea and are situated between $8^{\circ}-12^{\circ} \mathrm{N}$ lat. and $71^{\circ}-74^{\circ} \mathrm{E}$ long. The Gulf of Mannar is located between $8^{\circ} 47^{\prime} \mathrm{N}$ to $9^{\circ} 15^{\prime} \mathrm{N}$ lat. and $78^{\circ} 12^{\prime}-79^{\circ} 14^{\prime} \mathrm{E}$ long., on the southeastern coast of mainland India, consisting of 21 islands that lie between Rameswaram and Tuticorin in Tamil Nadu. Gulf of Kachchh coral reef region is located between $22^{\circ} 15^{\prime}-$ $23^{\circ} 40^{\prime} \mathrm{N}$ lat. and $68^{\circ} 20^{\prime}-70^{\circ} 40^{\prime} \mathrm{E}$ long. to the north of Saurashtra Peninsula of Gujarat. The marginal coral reef regions of Palk Bay in the Tamil Nadu coast and Malvan on the Maharashtra coast have not been considered in this study due to their relatively small spatial extent.

\section{Materials and methodology}

SST data for the present study were obtained from NOAA OISST version 2 high-resolution dataset available at ftp://eclipse.ncdc.noaa.gov/pub/OI-daily-v2/NetCDF/ 2017/AVHRR/ (ref. 24). This dataset has a spatial resolution of $0.25^{\circ} \times 0.25^{\circ}$ and temporal resolution of one day $^{25}$. NOAA OISST global data product provides daily SST data from 1982 to the present. This SST product uses advanced very high resolution radiometer (AVHRR) satellite data from NOAA Pathfinder SST. It was chosen for this study because of good agreement with in situ data from ships and buoys ${ }^{25}$. It also includes a large-scale adjustment of satellite biases with respect to in situ data. This high-resolution SST data product was developed using an optimum interpolation (OI) technique ${ }^{25}$.

SST data from NOAA OISST products for all five Indian regions were analysed for the three $\mathrm{MCB}$ years (1998, 2010 and 2016) in order to monitor the annual SST patterns and compute daily SST anomalies for the warmest period. The computation of long-term climatological means (hereafter referred as thermal threshold) of the warmest month (WM) SST was based on OISST data. The regional thermal thresholds were computed using the mean of WM SST individually for all five regions from 1982 to 2016 (35 year period). Bleaching threshold (BT) for coral bleaching is based on the concept of thermal threshold ${ }^{26}$. For this study BT is thermal threshold + $0.5^{\circ} \mathrm{C}$, as it was observed on the basis of an earlier exercise with long-term Hadley Sea Ice and Sea Surface Temperature version 1 (HadISST 1) data over Indian regions for relatively larger SST time series of 67 years $(1950-2016)^{27}$. The range of positive SST anomalies for Indian coral reef regions showing an association with

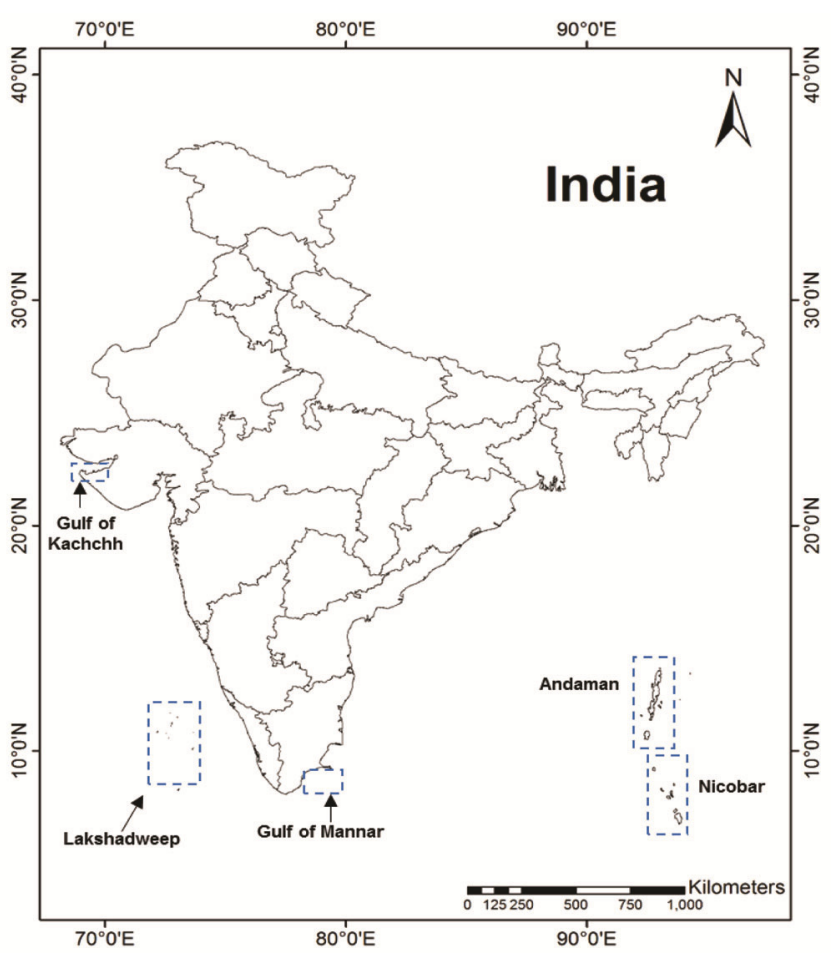

Figure 1. Study area of five Indian coral reef regions. 
Table 1. Warmest months, thermal thresholds and bleaching thresholds for Indian coral reefs regions based on NOAA OISST (1982-2016) data

\begin{tabular}{lccc}
\hline $\begin{array}{l}\text { Indian coral } \\
\text { reef regions }\end{array}$ & Warmest month & $\begin{array}{c}\text { Thermal } \\
\text { threshold }\left({ }^{\circ} \mathrm{C}\right)\end{array}$ & $\begin{array}{c}\text { Bleaching } \\
\text { threshold }\left({ }^{\circ} \mathrm{C}\right)\end{array}$ \\
\hline Andaman & May & $29.90( \pm 0.58)$ & 30.40 \\
Nicobar & May & $29.83( \pm 0.63)$ & 30.33 \\
Lakshadweep & May & $29.90( \pm 0.49)$ & 30.40 \\
Gulf of Mannar & April & $30.23( \pm 0.39)$ & 30.73 \\
Gulf of Kachchh & June & $29.35( \pm 0.45)$ & 29.85 \\
\hline
\end{tabular}

known $\mathrm{MCB}$ events was found to be from $0.56^{\circ} \mathrm{C}$ to $1.60^{\circ} \mathrm{C}$. The WMs, thermal thresholds and BTs for all five regions were found to be different (Table 1). Daily SST anomalies for the warmest periods during MCB events were also constructed on the basis of this thermal threshold. SST anomaly measures the magnitude of thermal stress conductive to coral bleaching ${ }^{20}$. SST anomaly is calculated as the difference between daily SST and thermal threshold. DHW measures the intensity and duration of thermal stress experienced by coral reefs ${ }^{19}$. This index represents the accumulation of positive SST anomaly at that location over the past 12 -week period ${ }^{28}$. The categories which are used to describe the severity of bleaching for Indian regions are no stress, bleach watch, warning, alert level-1 and alert level-2 based on DHW. The 'no stress' status is issued when the condition of $0^{\circ} \mathrm{C}<\mathrm{DHW}<2{ }^{\circ} \mathrm{C}$ weeks prevails. The 'bleach watch' status is issued when the condition of $2^{\circ} \mathrm{C}<\mathrm{DHW}<4^{\circ} \mathrm{C}$ weeks is met. The 'warning' status is issued when the condition of $4{ }^{\circ} \mathrm{C}<\mathrm{DHW}<6^{\circ} \mathrm{C}$ weeks is recorded. 'Alert level-1' is issued under the condition of $6^{\circ} \mathrm{C}<\mathrm{DHW}<$ $8^{\circ} \mathrm{C}$ weeks and 'alert level-2' is issued when the condition of $\mathrm{DHW}>8^{\circ} \mathrm{C}$ is satisfied.

\section{Results}

SST patterns during the known MCB years of 1998, 2010 and 2016 for the five Indian coral reef regions provide information on magnitude, duration of thermal stress and intensity experienced by these regions. The climatologically WM for Andaman, Nicobar and Lakshadweep was May, for Gulf of Mannar: April and for Gulf of Kachchh: June.

The Gulf of Mannar recorded maximum thermal threshold of $30.23^{\circ} \mathrm{C}\left( \pm 0.39^{\circ}\right)$ and the Gulf of Kachchh recorded minimum value of $29.35^{\circ} \mathrm{C}\left( \pm 0.45^{\circ}\right)$. The thermal thresholds for Andaman, Nicobar and Lakshadweep regions were $29.90^{\circ} \mathrm{C} \quad( \pm 0.58), 29.83^{\circ} \mathrm{C} \quad( \pm 0.63)$, $29.90^{\circ} \mathrm{C}( \pm 0.49)$ respectively, based on this study. Our analysis reveals the highest BT of $30.73^{\circ} \mathrm{C}$ for the Gulf of Mannar region and lowest BT of $29.85^{\circ} \mathrm{C}$ for the Gulf of Kachchh region.

This study shows that 2010 was the warmest among the three well-known MCB years for Andaman, Nicobar and the Gulf of Kachchh regions, while 2016 was the warmest for Lakshadweep and Gulf of Mannar regions (Figures 26). In all figures black line shows climatological mean SST (1982 to 2016) and dark red dash-dotted line shows thermal threshold for the region. For Andaman region, the year 2010 recorded the highest WM SST, which was $0.77^{\circ} \mathrm{C}$ higher than 1998 and $0.40^{\circ} \mathrm{C}$ higher than 2016 . For Nicobar region too, the year 2010 recorded the highest WM SST, which was $0.57^{\circ} \mathrm{C}$ higher than 1998 and $0.06^{\circ} \mathrm{C}$ higher than 2016. For Lakshadweep, the year 2016 recorded the highest WM SST and it is $0.15^{\circ} \mathrm{C}$ more than 1998 and $0.09^{\circ} \mathrm{C}$ more than 2010 . For Gulf of Mannar, 2016 recorded highest WM SST, which was $0.37^{\circ} \mathrm{C}$ higher than 1998 and $0.34^{\circ} \mathrm{C}$ higher than 2010 . For Gulf of Kachchh, the year 2010 recorded the highest WM SST and it was $0.86^{\circ} \mathrm{C}$ more than 1998 and $0.53^{\circ} \mathrm{C}$ more than 2016. The daily SST anomalies were derived for all five regions over the regional summers from March to July during 1998, 2010 and 2016 (Figures 2-6). The red bar in the figure shows positive anomaly and gray bar shows negative anomaly in all figures. Also, 2010 was found to be the most severe MCB year for Andaman, Nicobar and Gulf of Kachchh, while 2016 was the most severe for Lakshadweep and Gulf of Mannar.

For Andaman, the daily positive SST anomalies for 1998 were recorded for 61 out of 153 days of monitoring, while continuous SST anomalies were recorded for 43 days. The daily SST values crossed the thermal threshold during the first week of April and went below the thermal threshold in the second week of June with three very short intermittent breaks (Figure $2 b$ ). The highest daily SST anomaly of $1.87^{\circ} \mathrm{C}$ was observed on 9 May 1998. The cumulative stress or DHW for 1998 was $4.91^{\circ} \mathrm{C}$.

In 2010, the daily positive SST anomalies were recorded for 87 out of the 153 days. Continuous SST anomaly lasted for 75 days compared to 43 days for 1998. The daily SST values crossed the thermal threshold during the fourth week of March and went below the thermal threshold by the third week of June, with one intermittent break on 3 April. The highest daily SST anomaly of $2.16^{\circ} \mathrm{C}$ was observed on 9 May. The cumulative stress for 2010 was $11.72^{\circ} \mathrm{C}$. In 2016 , the daily positive SST anomalies were recorded for 53 out of 154 (leap year) days. The daily SST values crossed the thermal threshold during third week of April and went below the thermal 


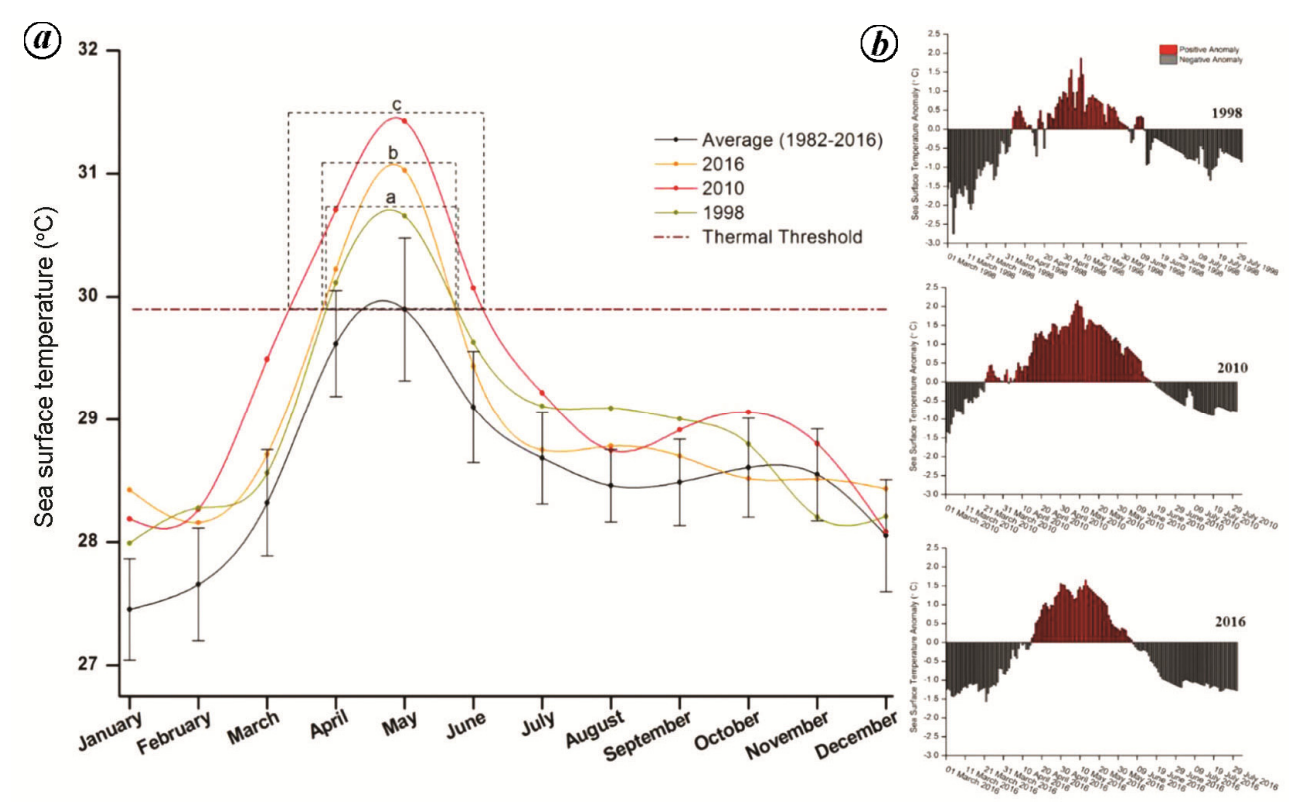

Figure 2. a Annual sea surface temperature (SST) patterns during mass coral bleaching (MCB) years 1998, 2010 and 2016 for Andaman (data source: ref. 24). b, Daily SST anomalies for Andaman region for the MCB years.
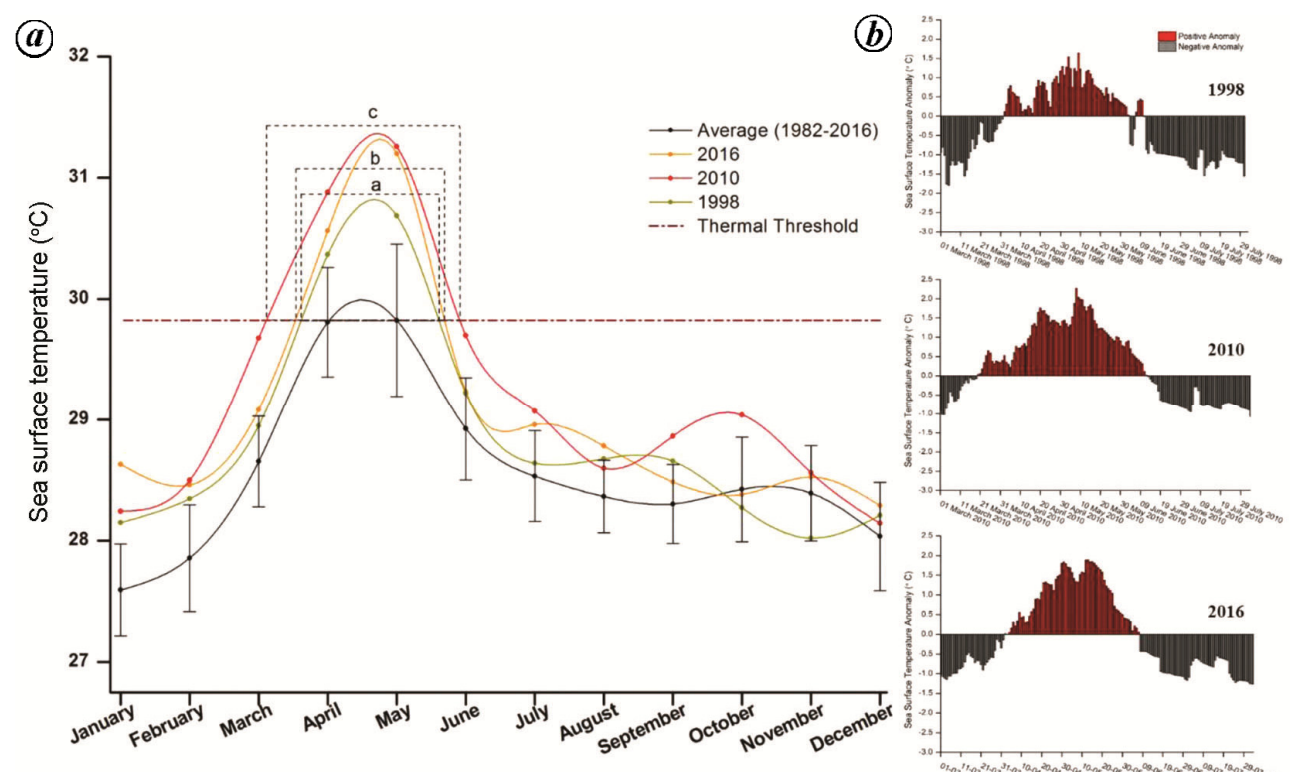

Figure 3. a Annual SST patterns during MCB years 1998, 2010 and 2016 for Nicobar (data source: ref. 24). $\boldsymbol{b}$, Daily SST anomalies for Nicobar region for the MCB years.

threshold in the first week of June without any intermittent break. The highest daily SST anomaly of $1.65^{\circ} \mathrm{C}$ was observed on 13 May. The cumulative stress for 2016 was $7.21^{\circ} \mathrm{C}$.

For Nicobar region, duration of daily positive SST anomalies for 1998 was recorded for 67 out of 153 days monitoring and continuous SST anomalies lasted for 63 days. The daily SST values crossed the thermal threshold during the first week of April and went below the thermal threshold in the second week of June, with one intermittent break (Figure $3 b$ ). The highest daily SST anomaly of $1.64^{\circ} \mathrm{C}$ was observed on 9 May. The cumulative stress for 1998 was $6.43^{\circ} \mathrm{C}$.

In 2010 , the daily positive SST anomalies were recorded for 85 out of 153 days. The daily SST values crossed the thermal threshold during the third week of March and went below the thermal threshold in the second week of June, without any intermittent break. The highest daily SST anomaly of $2.27^{\circ} \mathrm{C}$ was observed on 8 May. The cumulative stress for 2010 was $12.24^{\circ} \mathrm{C}$. In 2016 , the daily positive SST anomalies were recorded for 67 out of 154 (leap year) days. The daily SST values crossed the 


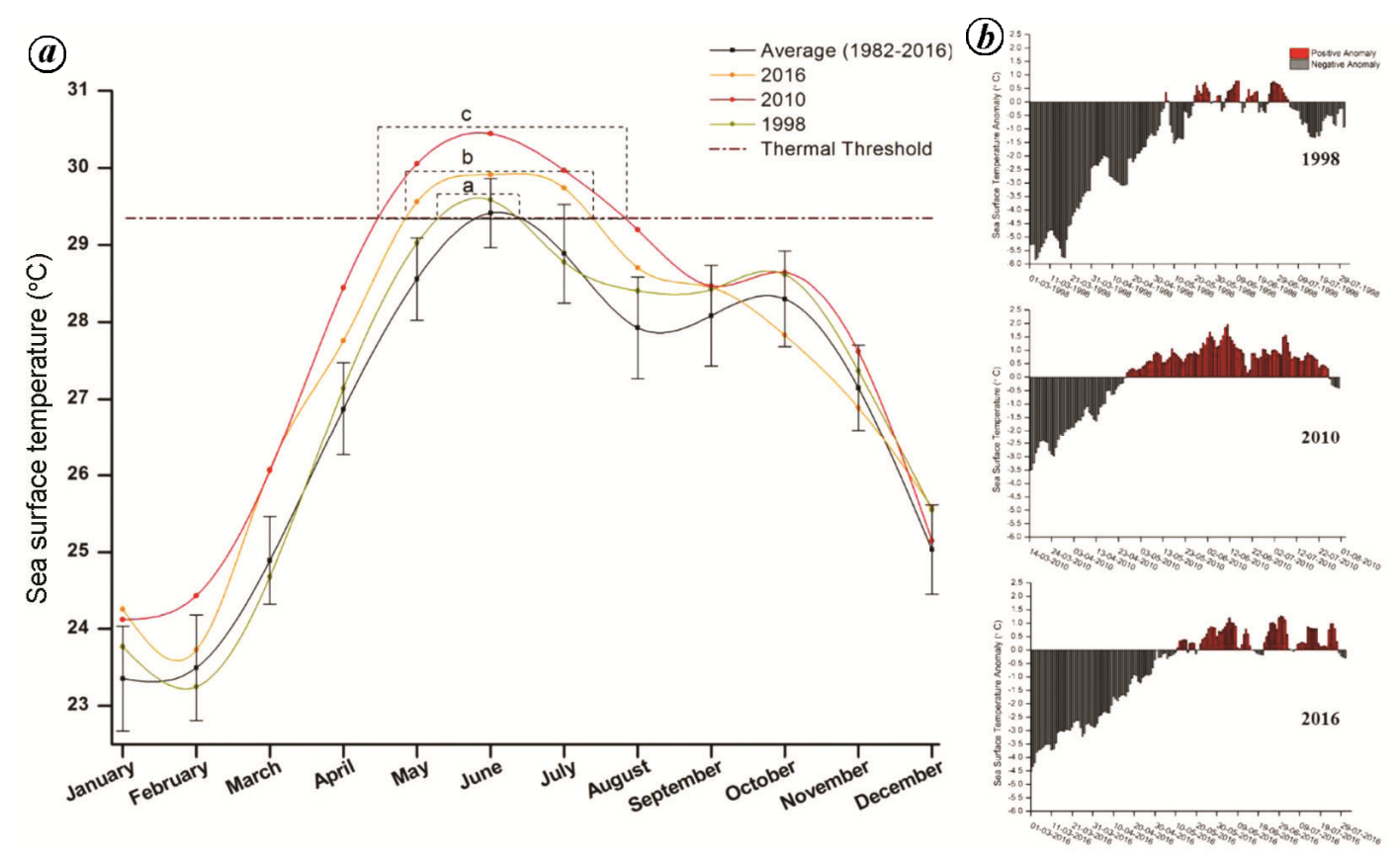

Figure 4. a Annual SST patterns during MCB years 1998, 2010 and 2016 for Gulf of Kachchh (data source: ref. 24). $\boldsymbol{b}$, Daily SST anomalies for Gulf of Kachchh region for the MCB years.

thermal threshold by the first week of April and went below the thermal threshold in the first week of June, without any intermittent break. The highest daily SST anomaly of $1.89^{\circ} \mathrm{C}$ was observed on 13 May. The cumulative stress for 2016 was $9.51^{\circ} \mathrm{C}$. The duration of daily positive SST anomalies for 1998 and 2016 was the same but cumulative stress values were different, indicating varying magnitude of thermal stress (Table 2).

For the Gulf of Kachchh region, the daily positive SST anomalies for 1998 were recorded for 37 out of 153 days and continuous SST anomalies lasted only for 10 days. The daily SST values in 1998 crossed the thermal threshold during the first week of May and went below the thermal threshold in the first week of July with five intermittent breaks (Figure $4 b$ ). The highest daily SST anomaly of $0.80^{\circ} \mathrm{C}$ was observed on 9 June. The cumulative stress for 1998 was $2.16^{\circ} \mathrm{C}$.

The daily positive SST anomalies for 2010 were recorded for 91 out of 153 days. The daily SST values crossed the thermal threshold during fourth week of April and went below the thermal threshold in the fourth week of July, without any intermittent break. The highest daily SST anomaly of $1.97^{\circ} \mathrm{C}$ was observed on 11 June. The cumulative stress for 2010 was $10.98^{\circ} \mathrm{C}$. In 2016 , the daily positive SST anomalies were recorded for 70 out of 154 days and continuous SST anomalies lasted for 62 days. The daily SST values crossed the thermal threshold during the second week of May and went below the thermal threshold in the fourth week of July, with four intermittent breaks. The highest daily SST anomaly of $1.27^{\circ} \mathrm{C}$ was observed on 30 June. The cumulative stress for 2016 was $5.57^{\circ} \mathrm{C}$.
For Lakshadweep region, the daily positive SST anomalies for 1998 were recorded for 68 out of 153 days, and continuous SST anomalies were observed for 65 days. The daily SST values in 1998 crossed the thermal threshold during the last week of March and went below the thermal threshold in the second week of June with two very short, intermittent breaks (Figure $5 b$ ). The highest daily SST anomaly of $1.24^{\circ} \mathrm{C}$ was observed on 30 May. The cumulative stress for 1998 was $6.17^{\circ} \mathrm{C}$.

The daily positive SST anomalies for 2010 were recorded for 73 out of 153 days and continuous SST anomalies lasted for 56 days. The daily SST values crossed the thermal threshold during the second week of March and went below the thermal threshold in the first week of June, with four intermittent breaks. The highest daily SST anomaly of $1.14^{\circ} \mathrm{C}$ was observed on 27 May. The cumulative stress for 2010 was $6.80^{\circ} \mathrm{C}$. In 2016 , the daily positive SST anomalies were recorded for 91 out of 154 days, and continuous SST anomalies lasted for 77 days. The daily SST value crossed the thermal threshold during the first week of March and went below the thermal threshold in the second week of June, with four intermittent breaks. The highest daily SST anomaly of $1.43^{\circ} \mathrm{C}$ was observed on 28 April. The cumulative stress for 2016 was $8.71^{\circ} \mathrm{C}$.

For the Gulf of Mannar region, daily positive SST anomalies for 1998 were recorded for 67 out of 153 days, and continuous SST anomalies lasted for 50 days. The daily SST values in 1998 crossed the thermal threshold during the last week of March and went below the thermal threshold in the second week of June, with three intermittent breaks (Figure $6 b$ ). The highest daily SST 
Table 2. Warmest month's sea surface temperature (SST), warmest month, SST anomaly, duration of thermal stress and degree heating weeks for mass coral bleaching years in the Indian coral reef regions

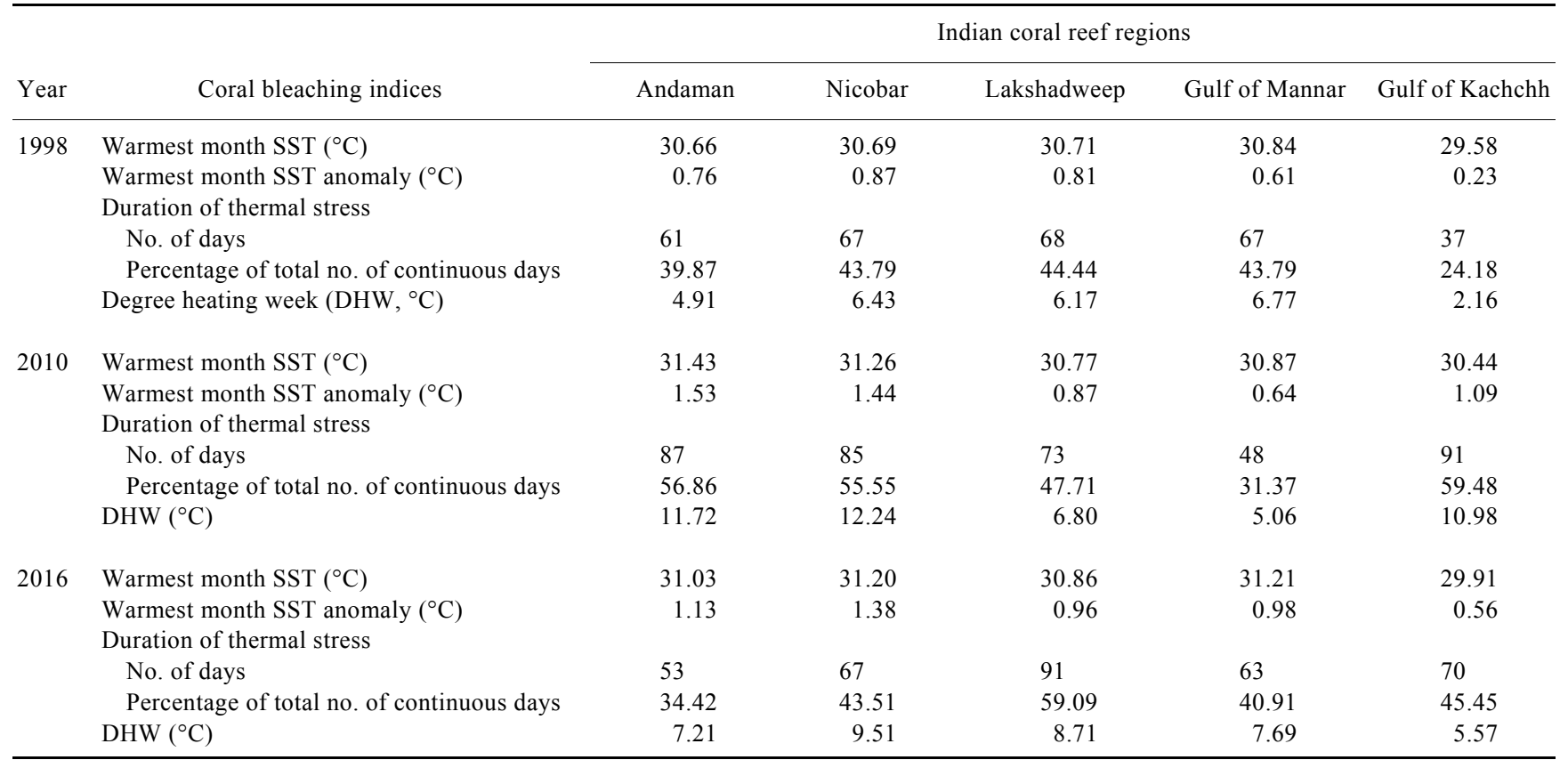

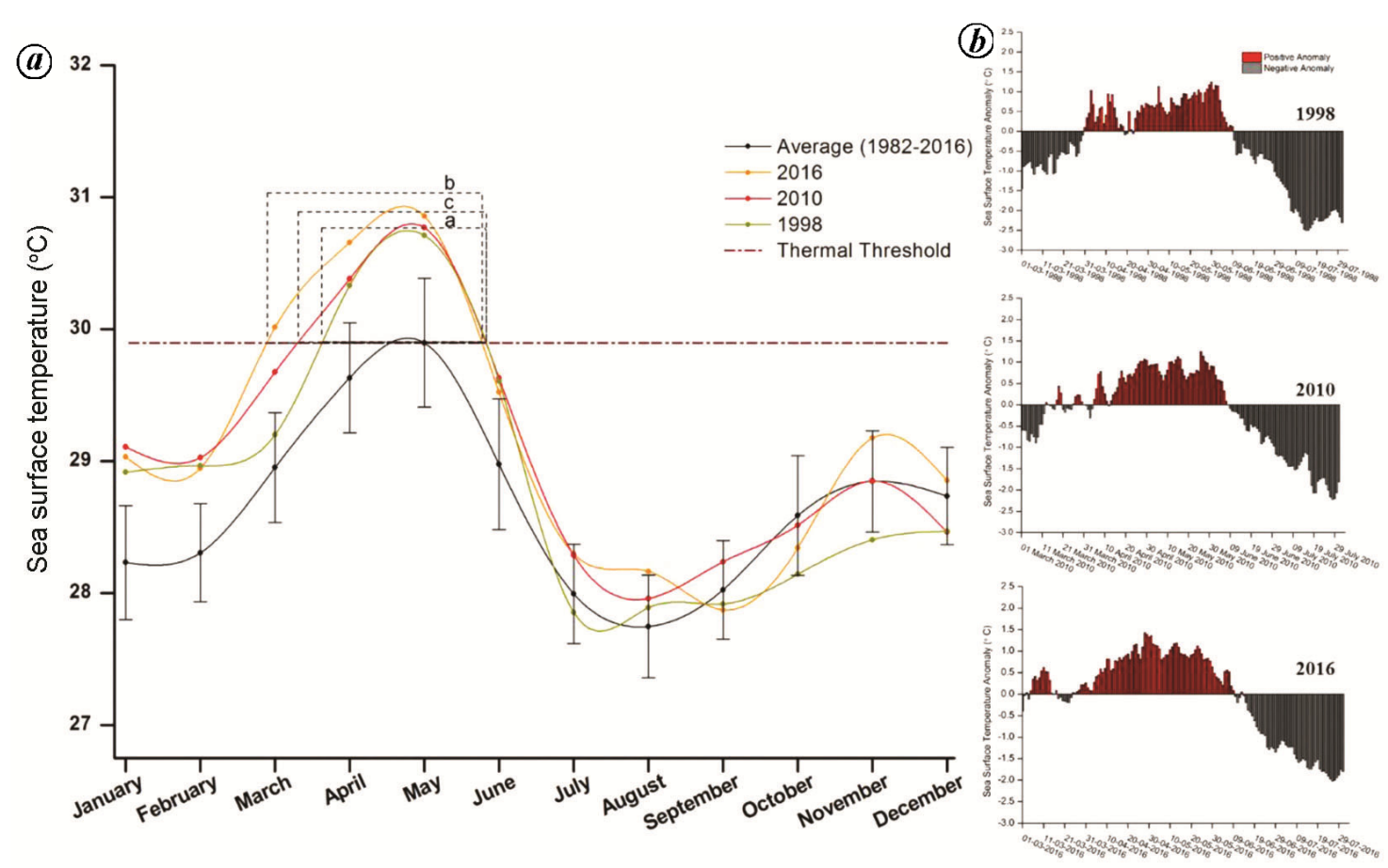

Figure 5. a, Annual SST patterns during MCB years 1998, 2010 and 2016 for Lakshadweep (data source: ref. 24). b, Daily SST anomalies for Lakshadweep region for the MCB years.

anomaly of $1.75^{\circ} \mathrm{C}$ was observed on 10 May. The cumulative stress for 1998 was $6.77^{\circ} \mathrm{C}$.

The daily positive SST anomalies for 2010 were recorded for 48 out of 153 days. The daily SST values crossed the thermal threshold during the first week of April and went below the thermal threshold in the third week of May, without any intermittent break. The highest daily SST anomaly of $1.23^{\circ} \mathrm{C}$ was observed on 10 April. The cumulative stress for 2010 was $5.06^{\circ} \mathrm{C}$. In 2016 , the daily positive SST anomalies were recorded for 63 out of the 154 days, and continuous SST anomalies lasted for 49 days. The daily SST values crossed the thermal 

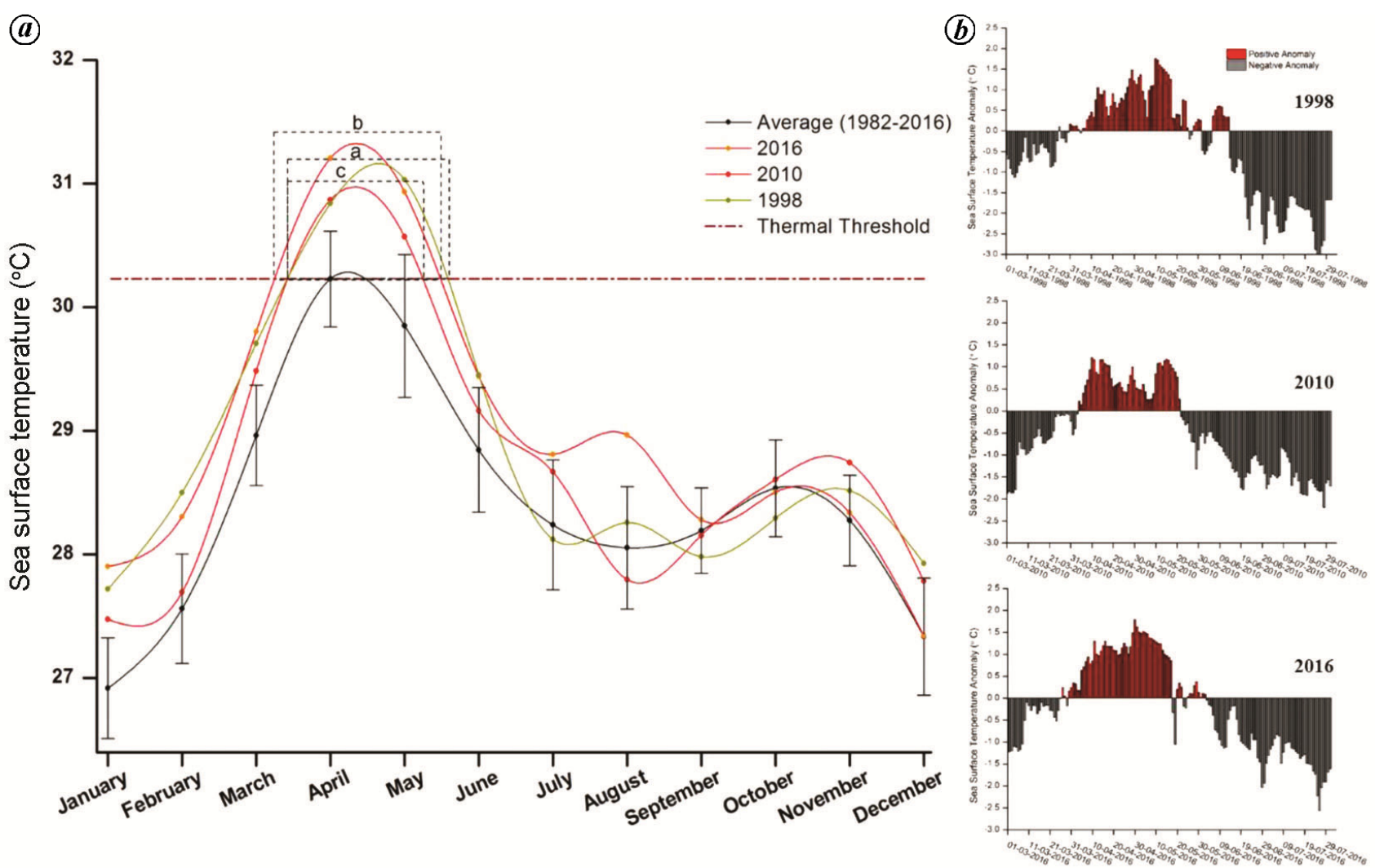

Figure 6. a, Annual SST patterns during MCB years 1998, 2010 and 2016 for Gulf of Mannar (data source: ref. 24). $\boldsymbol{b}$, Daily SST anomalies for Gulf of Mannar region for the MCB years.

threshold by the fourth week of March and went below the thermal threshold in the first week of June, with three very short intermittent breaks. The highest daily SST anomaly of $1.79^{\circ} \mathrm{C}$ was observed on 30 April. The cumulative stress for 2016 was $7.69^{\circ} \mathrm{C}$.

For the MCB years 1998, 2010 and 2016, we compared the regional values of maximum daily positive SST anomalies, duration of continuous spell of SST anomalies and commutative stress (DHW). It was found that 2010 recorded the highest thermal stress for Andaman, Nicobar and Gulf of Kachchh regions, while Lakshadweep and Gulf of Mannar experienced higher stress in 2016 (Table 2).

The study shows that, during the MCB years 1998, 2010 and 2016, the duration of thermal stress for Andaman region recorded 61,87 and 53 days, while DHWs were $4.91^{\circ} \mathrm{C}, 11.72^{\circ} \mathrm{C}$ and $7.21^{\circ} \mathrm{C}$ respectively. During 1998 , thermal stress was observed for 61 days, and DHW was $4.91{ }^{\circ} \mathrm{C}$ and for 2016: thermal stress was observed for 53 days, and $\mathrm{DHW}$ was $7.21^{\circ} \mathrm{C}$. The duration of thermal stress and DHW were monitored and found maximum for Andaman, Nicobar and Gulf of Kachchh regions in 2010, which recorded 'alert level-2' warning status according to the coral bleaching alert protocol developed at Space Applications Centre (ISRO), Ahmedabad. For Lakshadweep and Nicobar regions, the year 2016 recorded 'alert level-2' warning status, but for the Gulf of Mannar, thermal stress was maximum in 1998, while maximum DHW was recorded in 2016. The warning status for the Gulf of Mannar region was 'alert level-1'. During 2016, the warning status for Nicobar region was 'alert level-2' and Andaman region was under 'alert level-1'.

\section{Discussion}

Global coral bleaching events on routine recurrence are a relatively new phenomenon ${ }^{29}$. The first major, wellknown global coral bleaching event was declared in 1997-98 in connection with a strong El Niño event ${ }^{7}$. During 1997-98, MCB was reported from many coral reef countries $^{29}$, and about $16 \%$ of corals reefs experienced mortality worldwide ${ }^{1,30}$. The second global known MCB event was reported in 2010, and is known to be caused by an ENSO event ${ }^{7}$. The third global MCB event in 2016 was the longest one on record ${ }^{7}$. Coral bleaching is the most visible and widespread climate change event experienced by reefs. The GBR in Australia experienced unprecedented levels of coral death on a large scale during this third MCB event of 2015-16 (ref. 5). The 2015-16 El Niño and related ocean warming have generated significant coral bleaching and mortality worldwide $^{31}$. In the context of Indian reefs, coral bleaching was 
reported from Andaman and Nicobar during April 2016 by Indian National Centre for Ocean Information Services (INCOIS), Hyderabad. The Suganthi Devadason Marine Research Institute (SDMRI), Tuticorin, reported that unprecedented rise in SST killed $16 \%$ of corals in the Gulf of Mannar region between March and October 2016. In the Gulf of Kachchh region, a field visit was carried out to Laku Point reef near Poshitra village in 2016, to validate coral bleaching forewarning based on OISST data. A total of 13 coral species and a sea anemone were found bleached in various proportions during the field sampling after two months of prolonged thermal stress. The field data showed an average of $3.9 \%$ bleaching of corals at colony scale ${ }^{32}$. Maximum proportion of colony-scale bleaching was observed in Porites lutea species.

Coral bleaching also occurred along the entire coast of A\&N Islands during 2010 (ref. 33). About $74-77 \%$ corals were bleached in Andaman region from April to July 2010 (ref. 34). The bleaching of corals started in the first week of May 2010 and the branching corals (Acropora sp.) were the worst affected ${ }^{17}$. MCB was also observed in the reefs of Narara and Poshitra, Gulf of Kacchh region, covering $60-70 \%$ of the live coral colonies during May and June 2010 (ref. 35). During 1998, the coral reef areas of Andaman, Lakshadweep, Gulf of Mannar and Gulf of Kachchh experienced bleaching ${ }^{9,17}$. About $82 \%$ of coral cover in Lakshadweep region, $89 \%$ in Gulf of Mannar region and $11 \%$ in Gulf of Kachchh region showed signs of bleaching during April to July 1998 (ref. 9). Coral bleaching-related mortality was $26 \%$ in Lakshadweep and $23 \%$ in the Gulf of Mannar. There was no coral bleaching-related mortality in the Gulf of Kachchh region.

There are also reports of coral bleaching in the Andaman during 2002 and 2005, in Lakshadweep during 2002 and 2010, in the Gulf of Mannar in 2010 and in the Gulf of Kachchh in 2014 due to thermal stress ${ }^{15,36,37}$. During 2002 and $2005,20-40 \%$ of coral bleaching was observed in the Andaman ${ }^{17}$. Coral reefs in most of the A\&N Islands are at resilient stage after the major bleaching events of 1998, 2005 and 2010 (ref. 36). A sharp decline in live coral cover percentage was observed after the 2010 bleaching event in the Lakshadweep ${ }^{37}$, and its impact on associated organisms like sea anemones and giant clams was recorded ${ }^{38}$. On an average, $65 \%$ of the live corals in the reef flats were bleached during the 2010 bleaching event ${ }^{37}$. During April to May 2002, Lakshadweep also recorded high SST beyond the bleaching threshold and consequent coral bleaching occurred ${ }^{39}$.

Coral bleaching in Gulf of Mannar region during April 2010 was $72 \%$, this further increased to $85.1 \%$ (ref. 37). The influence of climate change on coral bleaching was observed in Pirotan Island, Gulf of Kachchh region, possibly due to combined influence of elevated SST, sedimentation and delayed monsoon during 2014-15 (ref. 40).

\section{Conclusion}

We conclude that the ecosystem response levels of Indian coral reef regions during $\mathrm{MCB}$ years are not spatiotemporally uniform. This study shows that 2010 is the high intensity MCB year for Andaman, Nicobar and Gulf of Kachchh regions, while for Lakshadweep and Gulf of Mannar regions, it is 2016 as compared to 1998 . Years 2010 and 2016 have rather surpassed the effects of MCB 1998. The three major MCB events have impacted the five major Indian coral reef regions within a span of 18 years from 1998, with recurrence interval of 12 and 5 years respectively. Hence it can be concluded, that there is a likelihood of high-intensity coral bleaching events in the future also. This study also highlights in the year 2010, the Nicobar region was observed to be the most vulnerable among the Indian coral reef regions according to DHW index.

1. Wilkinson, C. C., Status of Coral Reefs of the World: 2004, Australian Institute of Marine Science, Townsville, Australia, 2004.

2. Cesar. H., Burke, L. and Pet-Soede, L., The economics of worldwide coral reef degradation. Cesar Environment Economic Consulting, The Netherlands, 2013.

3. Crabbe, M. J., Climate change, global warming and coral reefs: modelling the effects of temperature. Comput. Biol. Chem., 2008, 32, 311-314.

4. Mumby, P. J., Hastings, A. and Edwards, H. J., Thresholds and the resilience of Caribbean coral reefs. Nature, 2007, 450, 98.

5. Frieler, K., Meinshausen, M., Golly, A., Mengel, M., Lebek, K., Donner, S. and Hoegh Guldberg, O., Limiting global warming to $2^{\circ} \mathrm{C}$ is unlikely to save most coral reefs. Nature Climate Change, 2013, 3, 165-170.

6. Anthony, K. R. N., Coral reefs under climate change and ocean acidification: challenges and opportunities for management and policy. Annu. Rev. Environ. Resour., 2016, 41, 59-81.

7. McField, M., Impact of climate change on coral in the coastal and marine environments of Caribbean Small Island Development States (SIDS). Caribbean Marine Climate Change Report Card: Science Review, 2017, 2017, pp. 52-59.

8. Marimuthu, N., Dharani, G., Vinithkumar, N. V., Vijayakumaran, M. and Kirubagaran, R., Recovery status of sea anemones from bleaching event of 2010 in the Andaman waters. Curr. Sci., 2011, 101, 734-736.

9. Arthur, R., Coral bleaching and mortality in three Indian reef regions during an El Niño southern oscillation event. Curr. Sci., 2000, 79, 1723-1729.

10. Lesser, M., Coral bleaching: cause and mechanisms. In Coral Reefs: An Ecosystem in Transition (eds Dubinsky, Z. and Stambler N.), Springer, Dordrecht, The Netherlands, 2011.

11. Brown, B., Coral bleaching: causes and consequences. Coral Reefs, 1997, 16, S129-S138.

12. Hoegh-Guldberg, O., Coral reef ecosystems and anthropogenic climate change. Reg. Environ. Change, 2011, 11, 215-227.

13. Eakin, C. M. et al., Caribbean corals in crisis: record thermal stress, bleaching, and mortality in 2005. PLOS ONE, 2010, 5, e13969.

14. Great Barrier Reef Marine Park Authority, Interim report: 2016 coral bleaching event on the Great Barrier Reef, GBRMPA, Townsville, Australia, 2016.

15. Kumar, T. A. and Balasubramanian, T., Bleaching of corals in Agatti-Lakshadweep, India: a window view. In Proceedings of the 12th International Coral Reef Symposium, Australia, 2012. 
16. Mohanty, P. et al., Coral bleaching along Andaman coast due to thermal stress during summer months of 2016: a geospatial assessment. Am. J. Environ. Protect., 2017, 6, 1-6.

17. Krishnan, P. et al., Elevated sea surface temperature during May 2010 induces mass bleaching of corals in the Andaman. Curr. Sci., 2011, 100, 111-117.

18. Baker, A., Glynn, P. and Riegl, B., Climate change and coral reef bleaching: an ecological assessment of long term impacts, recovery trends and future outlook. Estuarine Coastal Shelf Sci., 2008, 80, 435-471.

19. Strong, A. E., Barrientos C. S., Duda, C. and Sapper, J., Improved satellite techniques for monitoring coral reef bleaching. In Proceedings of the 8th International Coral Reef Symposium, Australia, 1997.

20. Liu, G., Strong, A. E. and Skirving, W., Remote sensing of sea surface temperature during 2002 barrier reef coral bleaching. EOS Trans. Am. Geophys. Union, 2003, 84, 137-141.

21. Gleeson, M. W. and Strong, A. E., Applying MCSST to coral reef bleaching. Adv. Space Res., 1995, 16, 151-154.

22. Eakin, C., Lough, J. and Heron, S., Climate Variability and Change: Monitoring Data and Evidence for Increased Coral Bleaching Stress In Coral Bleaching (eds Oppen M. J. H. and Lough, J. M.), Springer, Berlin, Germany, 2009.

23. Navalgund, R., Ajai, B., Ray Chaudhury, N., Bhattji, N., Madhupriya, N., Sharma, S. and Swaroop, P., Coral Reef Atlas of the World, SAC (ISRO), Ahmedabad, 2010.

24. National Centers for Environmental Information, NOAA, USA. OISST data available at http://eclipse.ncdc.noaa.gov/pub/OI-dailyv2/NetCDF/2017/AVHRR/.

25. Reynolds, R. W., Smith, T. M., Liu, C., Chelton, D. B., Casey, K. S. and Schlax, M. G., Daily high-resolution blended analysis for sea surface temperature. J. Climate, 2007, 20, 5473-5496.

26. Vivekanandan, E., Hussain Ali, M., Jasper, B. and Rajagopalan, M., Thermal thresholds for coral bleaching in the Indian seas. J. Mar. Bio. Ass. India, 2008, 50, 209-214.

27. Ray Chaudhury, N., Arora, M. and Gujrati, A., Mass coral bleaching responses from Indian coral reef regions as Chapter: 9. In Climate Change and The Vulnerable Indian Coast Under Section: Coastal Sensitivity (eds Bhatt, J. R. and Ramesh, R.), 2018, pp. 169-178.

28. Eladawy, A., Nadaoka, K., Negm, A., Saavedra, O. and Hanafy, M., Assessment of long term thermal stress on Egyptian coral reefs based on remotely sensed sea surface temperature data. Int. J. Environ. Sci. Dev., 2015, 6, 938-946.

29. Hoegh-Guldberg, O., Climate change, coral bleaching and the future of the World's coral reefs. Mar. Freshwater Res., 1999, 50, 839-866.

30. Lough, J., 1997-98: unprecedented thermal stress to coral reefs. Geophys. Res. Lett., 2000, 27, 3901-3904.

31. Ampou, E. E., Johan, O., Menkes, C. E., Niño, F., Birol, F., Ouillon, S. and Andréfouët S., Coral mortality induced by the
2015-2016 El-Niño in Indonesia: the effect of rapid sea level fall. Biogeosciences, 2017, 14, 817.

32. Arora, M., Chaudhury, N. R., Gujrati, A., Kamboj, R. D., Joshi, D., Patel, H. and Petal, R., Coral bleaching due to increased sea surface temperature in Gulf of Kachchh region, India during June 2016. Indian J. Geo. Mar. Sci., 2019, 48, 327-332.

33. Sadhukhan, K. and Raghunathan, C., Study on coral bleaching (2010) in Middle Andaman, Andaman and Nicobar Islands. Rec. Zool. Surv. India, 2012, 112, 27-34.

34. Marimuthu, N., Dharani, G., Vinithkumar, N. V., Vijayakumaran, M. and Kirubagaran, R., Recovery status of sea anemones from bleaching event of 2010 in the Andaman waters. Curr. Sci., 2011, 101, 734-736.

35. Joshi, D., Munjpara, S., Banerji, U. and Parasharya, D., Coral bleaching observations in the Gulf of Kachchh, India - a climate induced stress on the Scleractinians. J. Aquat. Biol. Fish, 2014, 2, $106-113$.

36. De, K., Venkataraman, K. and Ingole, B., Current status and scope of coral reef research in India: a bio-ecological perspective. Indian J. Geomar. Sci., 2017, 46, 647-662.

37. Manikandan, S., Ganesapandian, S., Singh, M., Anand, M. and Kumaraguru, A. K., Impact of climate change induced coral bleaching in the northern part of Gulf of Mannar and Palk Bay, southeast coast of India. J. Biol. Sci., 2014, 14, 276-283.

38. Idrees Babu, K. K. and Kumar, S. S., Status and changing trends of coral reefs in Lakshadweep archipelago after 1998 mass bleaching event - long term monitoring survey. Int. J. Appl. Pure Sci. Agric., 2016, 163-175.

39. Haritha, S., Raghukumar, C. and Dalal, S. G., Stress response of two coral species in the Kavaratti atoll of the Lakshadweep archipelago, India. Coral Reefs, 2005, 24, 463-474.

40. Adhavan, D., Kamboj, R. D., Marimuthu, N. and Bhalodi, M. M., Seasonal variation and climate change influence coral bleaching in Pirotan Island, Gulf of Kachchh Marine National Park, Gujarat. Curr. Sci., 2014, 107, 1780-1781.

ACKNOWLEDGEMENTS. We thank Director, Shri Tapan Misra; Deputy Director, Dr Raj Kumar; Group Director, Dr Prakash Chauhan, and Division Heads, Dr Bimal Kumar Bhattacharya and Dr R. P. Singh, Space Applications Centre (ISRO), Ahmedabad for their valuable suggestions, guidance and support during this study. We also thank National Oceanic and Atmospheric Administration (NOAA), USA for providing the NOAA OISST data in the public domain, and the reviewers for their valuable comments on this manuscript.

Received 27 September 2017; revised accepted 27 March 2019

doi: $10.18520 / \mathrm{cs} / \mathrm{v} 117 / \mathrm{i} 2 / 242-250$ 